\title{
Does food web theory work for marine ecosystems?
}

\author{
Jason Link* \\ Food Web Dynamics Program, Northeast Fisheries Science Center, National Marine Fisheries Service, \\ Woods Hole Laboratory, 166 Water Street, Woods Hole, Massachusetts 02543, USA
}

\begin{abstract}
More recent and extensive food web studies have questioned some of the prevailing paradigms of food web theory. Yet with few exceptions, most food webs and associated metrics are reported for freshwater or terrestrial systems. I analyzed the food web of the Northeast US Shelf ecosystem across a large spatial and temporal extent. This speciose food web exhibits a predator:prey ratio (0.95) and percentage of intermediate species (89\%) similar to most other food webs. Other statistics, such as the percentage of omnivory (62\%), percentage of cannibalistic species (31\%), number of cycles $(5 \%)$, and the total number of links $(L ; 1562)$ and species $(S ; 81)$ are similar to more recent and extensively studied food webs. Finally, this food web exhibits a linkage density $(L / S ; 19.3)$, connectivity $\left(C_{i} 48.2 \%\right)$, and Lyapunov stability proxy $\left(S \times C_{i} 39.1\right)$ that are an order of magnitude higher than other webs or are disproportionate to the number of species observed in this system. Although the exact $S$ and $C$ relationship is contentious, the connectivity of food webs with more than 40 species is approximately $10 \%$, which is very different from the near $50 \%$ observed for this ecosystem. The openness of marine ecosystems, lack of specialists, long lifespans, and large size changes across the life histories of many marine species can collectively make marine food webs more highly connected than their terrestrial and freshwater counterparts, contrary to food web theory. Changes in connectivity also have ramifications for ecosystem functioning and Lyapunov stability. The high connectivity of this food web and the mathematical determinants for stability are consistent with the weak nature of species interactions that have been observed and that are required for system persistence. Yet the historically high exploitation rates of marine organisms obfuscate our understanding of marine food web stability. It is possible that marine food webs are inherently very different from their terrestrial or freshwater counterparts, implying the need for modified paradigms of food web theory.
\end{abstract}

KEY WORDS: Connectivity $\cdot$ Stability $\cdot$ Species interactions $\cdot$ Continental shelf $\cdot$ Predator $\cdot$ Prey · Food web dynamics

Resale or republication not permitted without written consent of the publisher

\section{INTRODUCTION}

Food webs are a useful framework to assess the magnitude and importance of trophic relationships in an ecosystem. Food webs have high heuristic value for ecological theory, and food web linkages ultimately determine the fate and flux of every population in an ecosystem, particularly upper trophic levels of fiscal importance (May 1973, Pimm 1982). Thus, in the past 2 decades food web synthesis has not only generated a

*E-mail: jlink@whsun1.wh.whoi.edu host of theoretical debate that has been, mostly, fruitful and has directed a lot of empirical and experimental work, but has also often provided an interesting, if not useful, context for management applications (Crowder et al. 1996, Winemiller \& Polis 1996). At the least, food web characterization is required as an initial step in understanding an ecosystem.

Several food web metrics can provide insight into the dynamics of biomass partitioning and production in an ecosystem (May 1973, Pimm 1982, Cohen et al. 1990). Central among these parameters are species richness $(S)$ and the number of species interactions or links $(L)$, with many other emergent properties and statistics 
derived from these metrics. Reviews have questioned either the usefulness of reporting topological web statistics or the validity of the data from which they were derived (e.g. Polis 1991, Hall \& Raffaelli 1993, Warren 1994, Winemiller \& Polis 1996). Also important are the effects of spatial, temporal and taxonomic resolution on detecting $S$ and $L$ (Hall \& Raffaelli 1991, 1993, Martinez 1993, Goldwasser \& Roughgarden 1997, Solow \& Beet 1998, Martinez et al. 1999). However, there is value in examining these metrics, particularly for comparison of ecosystems using webs constructed with similar criteria (Winemiller 1990, Pimm et al. 1991, Cohen et al. 1993, Goldwasser \& Roughgarden 1993, Reagan et al. 1996, Rafaelli 2000).

The relationship among the different food web metrics and their interpretation is contentious. Connectance and linkage hypotheses contradict whether or not an increasing $S$ causes connectivity $(C)$ to hyperbolically decline (Cohen \& Newman 1988, Winemiller 1990, Martinez 1992, Hall \& Raffaelli 1993, Warren 1994). This is true with changes in the level of taxonomic, spatial or temporal aggregation in a single web or across webs with different numbers of species. An implication from this relationship is that another inference derived from $S, L$, and $C$ is an assessment of system Lyapunov stability (May 1973, Pimm 1982, DeAngelis 1992), where Lyapunov stability defines a local or 'neighborhood' equilibrium (think of a ball on top of a steep hill; it is not locally stable if perturbed). There is disagreement whether higher $C$ increases, decreases, or has alternating effects on overall stability, regardless of whether we should even be solving for or assuming equilibrium conditions (Pimm 1984, Haydon 1994, de Ruiter et al. 1995). However, the role of interaction strength is clearly important in the debate over the determinants of system stability (McCann et al. 1998, Closs et al. 1999).

Some of the more recent and extensive food web studies are inconsistent with earlier generalizations and catalogs of food webs (e.g. Warren 1989, Winemiller 1990, Hall \& Raffaelli 1991, Martinez 1991, Polis 1991, Goldwasser \& Roughgarden 1993, Reagan et al. 1996). Most of these food webs, with few exceptions, have been derived from freshwater or terrestrial systems. Those food webs that have been constructed for marine systems generally do not present these standard macrodescriptors or are often limited to coastal, estuarine, or similar systems (e.g. Paine 1966, Menge \& Sutherland 1976, Baird \& Ulanowicz 1989, Christensen \& Pauly 1993, Monaco \& Ulanowicz 1997). The few examples that do present these statistics for marine food webs face the same limitations of earlier food web catalogues (e.g. Arreguin-Sanchez et al. 1993, Gomes 1993, Mendoza 1993); i.e. a low number of species, a high level of species aggregation, a limited spatio- temporal extent of study, and a low probability of detecting $S$ or $L$. Raffaelli (2000) emphatically calls for much more research on marine food webs. In this study, I present a topological food web and associated statistics for the Northeast US Shelf ecosystem food web.

\section{METHODS}

I constructed the food web of the Northeast US Shelf ecosystem based primarily upon stomach content evaluation conducted as part of a National Marine Fisheries Service monitoring program. More extensive details of this program and sampling are described elsewhere (Link \& Almeida 2000). Very briefly, the food habits of over 120 species of fish and invertebrates, from over 300000 individuals, have been examined since 1973, ranging from Cape Hatteras, NC, to the Gulf of Maine. The number of prey types (i.e. linkages) asymptotes for most species between 500 and 1000 stomachs examined (Link \& Almeida 2000), and most of these species had at least that many individuals collected. I selected 81 trophic 'species' (i.e. groups of organisms at taxonomically feasible and functionally related levels) common in the northwest Atlantic, including humans. The lowest trophic level is highly aggregated (i.e. phytoplankton, detritus), yet there are 33 groups/species of invertebrates at the next trophic levels, as well as 41 species/groups of fish. Admittedly, this food web is vertebrate centric, and is, like all food webs, by default incomplete.

Recognizing the potential effects of spatial, temporal, and taxonomic aggregation (Warren 1989, Winemiller 1990, Hall \& Raffaelli 1991, 1993, Martinez 1993, Goldwasser \& Roughgarden 1997, Solow \& Beet 1998, Martinez et al. 1999), I chose to present a static and inclusive web for 3 reasons. First, the goal of this work was to characterize this food web as exhaustively as possible in order to capture all species interactions. Detailing the spatial or temporal dynamics of this food web, appropriate species assemblages, and interaction strengths are certainly important but are beyond the scope of this work (and are described elsewhere; e.g. Sissenwine et al. 1982, Garrison 2000, Garrison \& Link 2000, Overholtz et al. 2000, Link \& Garrison 2002). Second, I examined 2, 3, and 5 yr time blocks of the food web (not presented) across the time series and only observed a 1 to $2 \%$ decline in the number of linkages and no change in the number of species. A similar exercise for different spatial components of the ecosystem resulted in a similar response, primarily lowering the number of species in any given region by 2 to $5 \%$. Third, it is generally recognized that a cumulative web is a more complete and accurate portrayal of trophic interactions. 
I constructed an interaction matrix of the 81 pairwise interactions, and assigned a $-1,0$ or +1 depending on whether Species A preyed on, did not interact with, or was eaten by Species B respectively (emphasizing the half matrix). The presence or absence of a species in the diet of another species was the primary determinant of these values, and did not rely on an index of interaction strength. A food web diagram was then assembled from these trophic linkages. I then calculated standard food web metrics for this web (May 1973, Pimm 1982, Cohen 1989, Cohen et al. 1990) and contrasted these to similar macrodescriptor metrics from more recent and extensive food webs.

The first metric noted was simply the number of species $(S)$. The number of interactions or trophic links $(L)$ was also counted. This number was then divided by the total number of possible interactions to determine the connectivity $(C)$ of a system:

$$
C=\frac{L}{S(S-1) / 2}
$$

This method of calculating $C$ implies the half matrix without the diagonal interactions. The number of interactions per species $(L / S)$ was also calculated. I also examined directed connectance (Martinez 1991, 1992), where $C_{\text {dir }}$ is equal to $L / S^{2}$. Both $C$ and $L / S$ index the level of interactions, potential competition, trophic specialization, and overall inter-connectedness of a food web (May 1973, Pimm 1982, 1991, Cohen et al. 1993). The product $S \times C$, when coupled with an assessment of overall web interaction strength, either mean interaction strength (May 1973) or eigenvalues of the interaction matrices (Pimm 1982), can give an assessment of the overall mathematical stability for a system. It has been implied that if the square root of the product $S \times C$ multiplied by the mean interaction strength is less than unity, a system will be stable (May 1973). Given that constraint, I calculated a proxy for stability based upon the observed $S \times C$ values.

The number of basal species (no trophic levels supporting these organisms), the number of top predators (defined here as a species having less than 2 predators, excluding humans), and the total number of intermediate species (non basal and non top predator species) were enumerated, as were the number of cannibals (species known to prey upon other individuals of their own species; i.e. the diagonal of the interaction matrix), the number of cycles (when Species A preys upon Species B and vice versa), and the number of omnivores (defined as the number of species eating prey from more than 1 trophic level; Pimm \& Lawton 1978). The number of predators for a prey item, the number of prey items for a predator, and the predator to prey ratio were also calculated.

\section{RESULTS AND DISCUSSION}

\section{Similarities across all food webs}

The first thing to note is that the US Northeast Shelf ecosystem has a speciose, highly connected food web (Fig. 1). The complexity exhibited in this diagram mimics similar 'bird's nests' from other studies. The number of species is generally higher than catalogs from the late 1980s and early 1990s, but similar to more recent studies (Table 1). The allocation of the species across trophic levels is similar to most other food webs, with the intermediate species generally comprising at least $50 \%$ of all species (Fig. 2). When comparing more expansive webs to the Cohen et al. (1990) catalog, this pattern details the improved trend of de-emphasizing top consumers and the continued trend of poor treatment for lower trophic levels. I recognize the high degree of aggregation at lower trophic levels in the Northwest Atlantic web, but 33 invertebrate groups is larger than many whole food webs that have been examined (Cohen 1989, Schoener 1989, Cohen et al. 1990, Polis 1991, Polis \& Strong 1996). The number of observations on the feeding habits for this number of species is unusually high, yet by no means exhaustive.

The predator to prey ratio observed in this study is similar to most food webs (Table 1). Although recognized as a potential artifact of double counting species (Closs et al. 1993), the most likely reason why this ratio is so consistent across vastly different food webs is our generally poor treatment of lower trophic levels. This ratio suggests that this web is not as vertebrate (or top predator) centric as earlier examples.

\section{Similarities with more recent and extensive food webs}

The value for the mean number of interactions per species (linkage density; 19.3) confirms that this is a highly connected food web (Fig. 3). Only the studies of Martinez (1991) and Reagan et al. (1996) of tropical lakes and a tropical rain forest, respectively, exhibit similar magnitudes of linkage density. It is interesting to note that higher linkage density values $(\geq 5)$ are associated with tropical or neotropical ecosystems. The US Northeast Shelf ecosystem is a system where biogeographical provinces, ranging from boreal to temperate to sub-tropical, converge and produce high species richness (Sherman et al. 1996). Perhaps mixing this high number of species contributes to the high linkage density observed in this ecosystem.

The connectivity for this food web is also high, similar in magnitude to the desert food web of Polis (1991) and the small lake food webs of Sprules \& Bowerman 


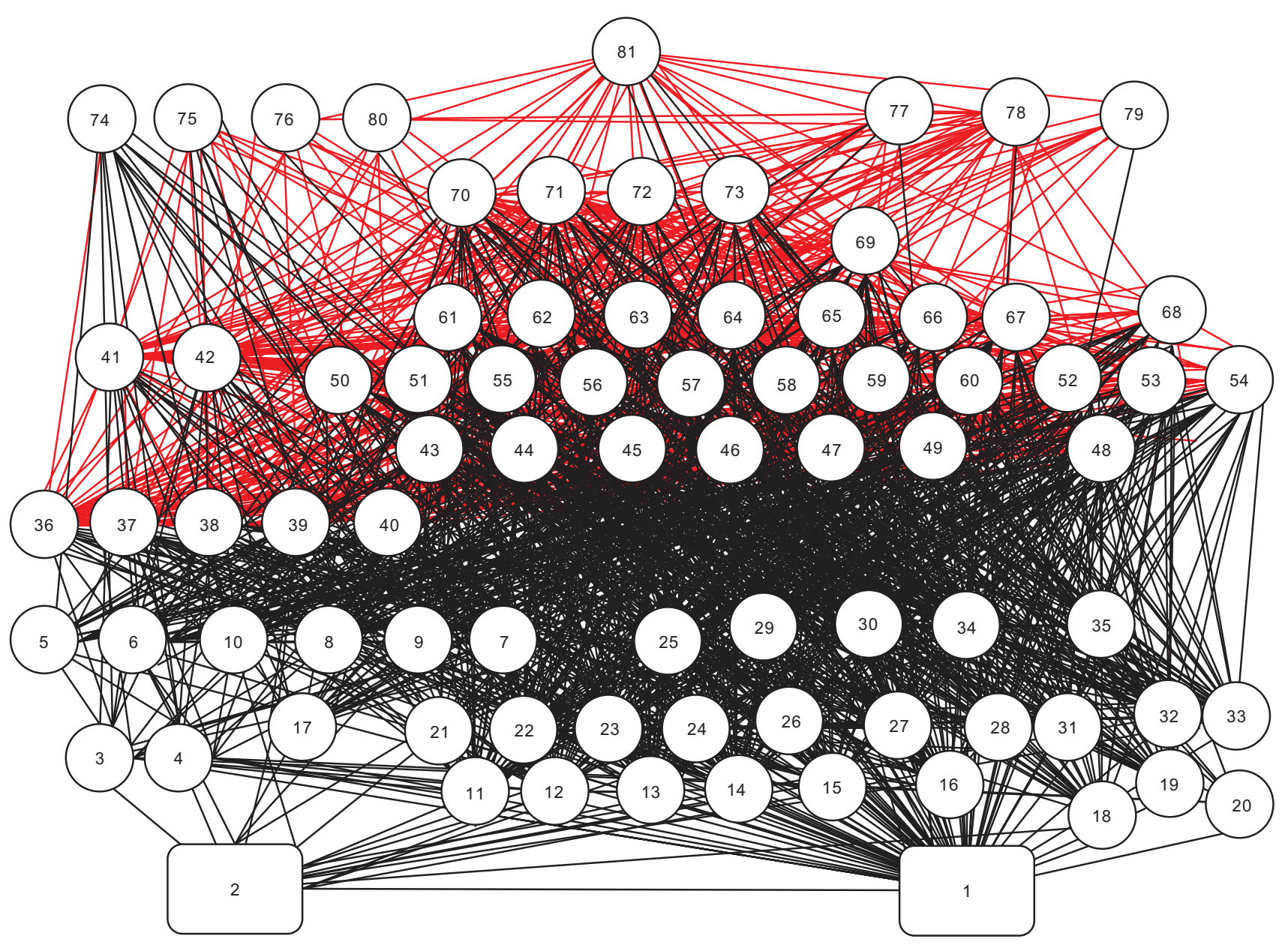

Fig. 1. Species and links of the northwest Atlantic food web. This tangled 'bird's nest' represents interactions at the approximate trophic level of each species, with increasing trophic level towards the top of the web. The left side of the web generally typifies pelagic organisms, and the right to middle represents more benthic/demersally oriented organisms. Red lines indicate predation on fish. 1 = detritus, $2=$ phytoplankton, $3=$ Calanus sp., $4=$ other copepods, $5=$ ctenophores, $6=$ chaetognatha (i.e. arrow worms), $7=$ jellyfish, $8=$ euphasiids, $9=$ Crangon sp., $10=$ mysids, $11=$ pandalids, $12=$ other decapods, $13=$ gammarids, $14=$ hyperiids, 15 = caprellids, $16=$ isopods, $17=$ pteropods, $18=$ cumaceans, $19=$ mantis shrimps, $20=$ tunicates, $21=$ porifera, $22=$ cancer crabs, 23 = other crabs, $24=$ lobster, $25=$ hydroids, $26=$ corals and anemones, $27=$ polychaetes, $28=$ other worms, $29=$ starfish, $30=$ brittle stars, $31=$ sea cucumbers, $32=$ scallops, $33=$ clams and mussels, $34=$ snails, $35=$ urchins, $36=$ sand lance, $37=$ Atlantic herring, 38 = alewife, $39=$ Atlantic mackerel, $40=$ butterfish, $41=$ loligo, $42=$ illex, $43=$ pollock, $44=$ silver hake, $45=$ spotted hake, $46=$ white hake, $47=$ red hake, $48=$ Atlantic cod, $49=$ haddock, $50=$ sea raven, $51=$ longhorn sculpin, $52=$ little skate, $53=$ winter skate, $54=$ thorny skate, $55=$ ocean pout, $56=$ cusk, $57=$ wolfish, $58=$ cunner, $59=$ sea robins, $60=$ redfish, $61=$ yellowtail flounder, 62 = windowpane flounder, $63=$ summer flounder, $64=$ witch flounder, $65=$ four-spot flounder, $66=$ winter flounder, $67=$ American plaice, $68=$ American halibut, $69=$ smooth dogfish, $70=$ spiny dogfish, $71=$ goosefish, $72=$ weakfish, $73=$ bluefish, $74=$ baleen whales, $75=$ toothed whales and porpoises, $76=$ seals, $77=$ migratory scombrids, $78=$ migratory sharks, $79=$ migratory billfish, 80 = birds, $81=$ humans

(1988) and Warren (1989) (Table 1). With very few exceptions connectivity rarely approaches $50 \%$. Recent studies demonstrate that $S$ is typically greater than is initially ascertained, and as long term ecological research continues, it will likely continue to expand (Martinez 1993, Goldwasser \& Roughgarden 1997, Martinez et al. 1999). That is, both the spatial and temporal scales of other studies suggest that, at least for some types of ecosystems, extending the period of observation may increase $S$ and $L$, and by extension,
$L / S$ and $C$. Given the spatial and temporal extent of this study, it is highly probable that $S, L, L / S$ and $C$ have been adequately represented for this ecosystem.

Cannibalism and cycles are notable in this food web (Table 1). Empirical reviews have confirmed that these are more frequent phenomena than was previously hypothesized (Polis et al. 1989, Winemiller 1990, Polis 1991, Reagan et al. 1996). These phenomena have intriguing implications for marine populations, particularly as they may limit recruitment of commercially valuable stocks. 
Table 1. Major food web metrics from catalogs and more extensive webs. $S=$ number of species, $C=$ connectivity, $S \times C=$ Lyapunov stability proxy, Predator/Prey $=$ the ratio of predators to prey, Cycles $=$ species that mutually prey on each other, Cann. = cannibalistic species, $L=$ number of links

\begin{tabular}{|c|c|c|c|c|c|c|c|c|}
\hline Source & $S$ & $C$ & $S \times C$ & $\begin{array}{l}\text { Predator/ } \\
\text { Prey }\end{array}$ & $\%$ Cycles & \% Cann. & $L$ & $\begin{array}{l}\text { Type of } \\
\text { ecosystem }\end{array}$ \\
\hline \multicolumn{9}{|l|}{ Catalogs (mean values) } \\
\hline $\begin{array}{l}\text { Cohen 1989, Cohen et al. } \\
\text { 1990, (ECOWEB; extends } \\
\text { Briand \& Cohen 1987) }\end{array}$ & $\begin{array}{c}\text { Mean = } 17 \\
\text { Range 3-48 }\end{array}$ & 27.3 & 4.6 & 1.18 & $<1$ & $<1$ & 31 & Mixed \\
\hline Schoenly et al. 1991 & $\begin{array}{c}\text { Mean }=24 \\
\text { Range 3-90 }\end{array}$ & 19.2 & 4.6 & 0.64 & $<1$ & $<1$ & 53 & $\begin{array}{c}\text { Mixed: } \\
\text { mainly terrestrial }\end{array}$ \\
\hline Havens 1992 & $\begin{array}{c}\text { Mean }=38 \\
\text { Range 10-74 }\end{array}$ & 21.1 & 8.0 & - & - & - & 148 & $\begin{array}{l}\text { Aquatic: mainly } \\
\text { lakes and ponds }\end{array}$ \\
\hline \multicolumn{9}{|l|}{ Comprehensive webs } \\
\hline Sprules \& Bowerman 1988 & 12 & 54.4 & 6.5 & - & 17 & 25 & 36 & Aquatic: lake \\
\hline Warren 1989 & 22 & 47.6 & 10.4 & 0.66 & - & - & 110 & Aquatic: pond \\
\hline Polis 1991 & 30 & 66.4 & 9.0 & 0.90 & 53 & 74 & 409 & Terrestrial: desert \\
\hline $\begin{array}{l}\text { Tavares-Cromar } \\
\text { \& Williams } 1996\end{array}$ & 34 & 19.4 & 6.5 & - & - & - & 109 & Aquatic: stream \\
\hline Closs \& Lake 1994 & 40 & 10.2 & 4.1 & - & - & - & 80 & Aquatic: stream \\
\hline $\begin{array}{l}\text { Goldwasser \& } \\
\text { Roughgarden } 1993\end{array}$ & 44 & 23.0 & 10.1 & 1.03 & - & - & 218 & $\begin{array}{l}\text { Terrestrial: } \\
\text { tropical } \\
\text { rain forest }\end{array}$ \\
\hline Winemiller 1990 & 75 & 18.5 & 13.9 & - & - & - & 514 & $\begin{array}{c}\text { Aquatic: } \\
\text { swamps, streams }\end{array}$ \\
\hline Martinez et al. 1999 & 77 & 4.3 & 3.3 & - & - & - & 126 & $\begin{array}{l}\text { Terrestrial: } \\
\text { grasslands }\end{array}$ \\
\hline Hall \& Raffaelli 1991 & 92 & 9.7 & 9.0 & 0.72 & - & - & 409 & Estuary \\
\hline Reagan et al. 1996 & 136 & 14.4 & 19.6 & - & 35 & In cycles & 1322 & $\begin{array}{l}\text { Terrestrial: trop- } \\
\text { ical rain forest }\end{array}$ \\
\hline Martinez 1991 & 182 & 14.4 & 26.2 & 1.14 & - & - & 2366 & Aquatic: lakes \\
\hline This study & 81 & 48.2 & 39.1 & 0.95 & 5 & 31 & 1562 & $\begin{array}{c}\text { Marine: } \\
\text { Continental Shelf }\end{array}$ \\
\hline
\end{tabular}

There is evidence that generalist, omnivorous predators are also more common than previously thought (Polis \& Strong 1996, McCann et al. 1998, Closs et al. 1999). Two major points emerge from the high connectivity observed for this food web: (1) there are a lot of generalists (i.e. broad diet compositions) in this ecosystem; and (2) there is a high degree of omnivory (i.e, feeding at more than 1 trophic level; Fig. 4) for these component organisms. Other studies of this ecosystem have documented the broad diets, similar functionality, and the ability of these species to rapidly switch to more abundant prey items, often at different trophic levels (Sissenwine et al.

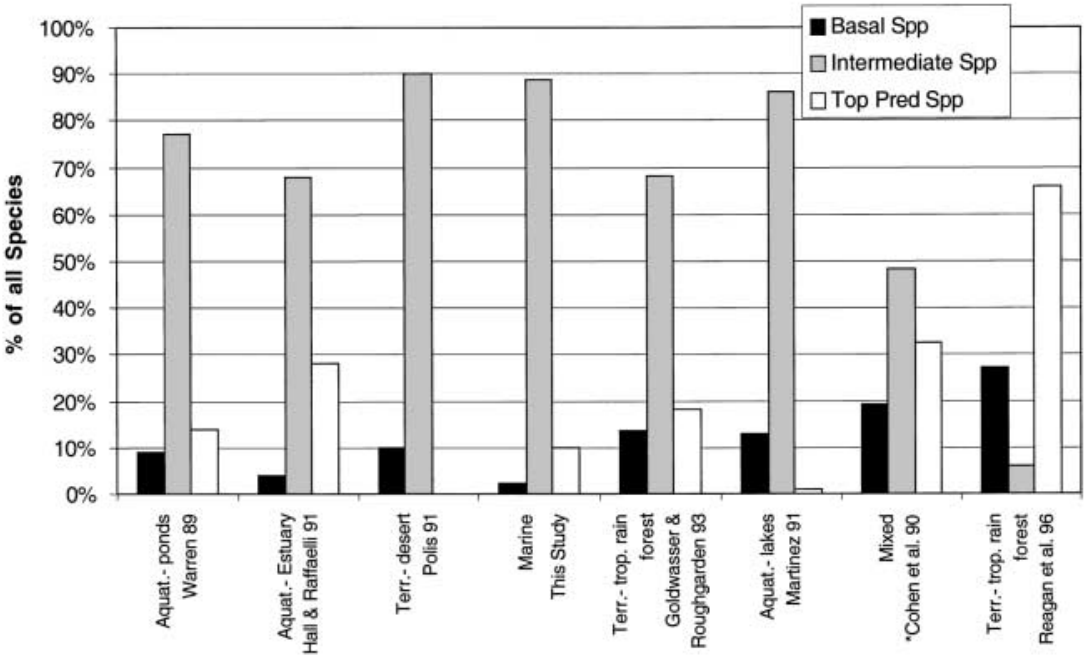

Fig. 2. Allocation of species in lower, middle, and upper trophic levels from various food webs 


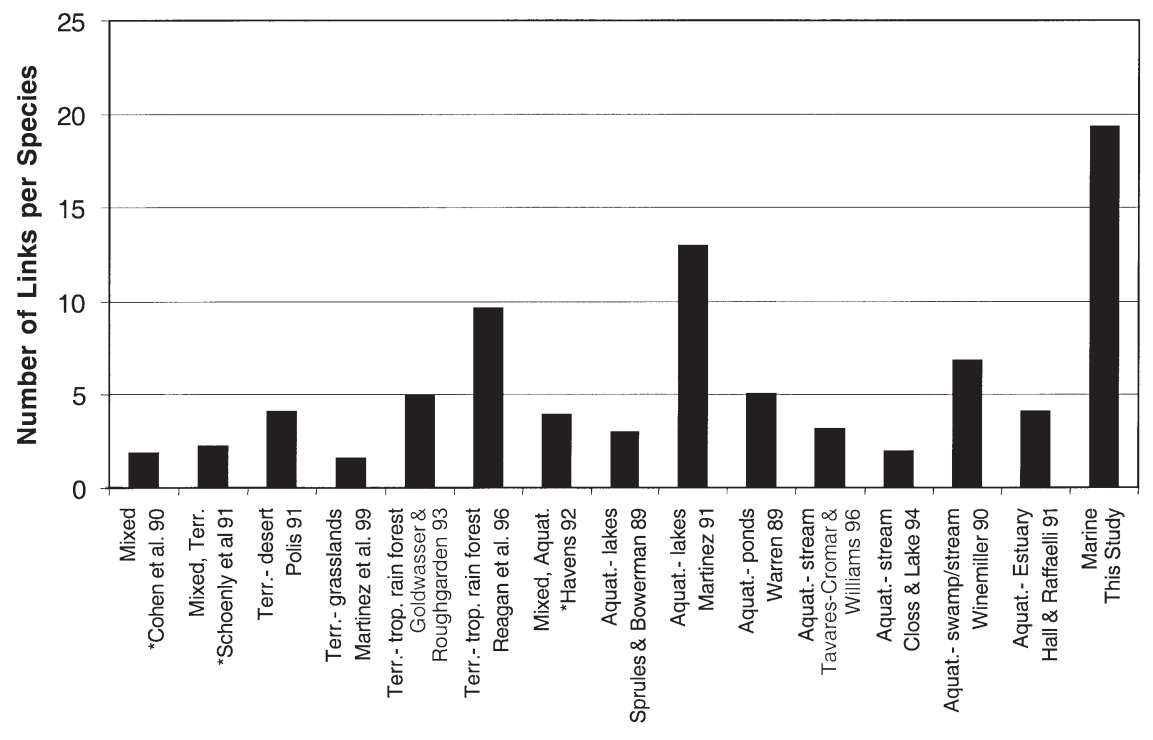

Fig. 3. Linkage density of various food webs

\section{Uniqueness of marine food webs and implications for system stability}

If one examines the level of connectivity in this system in relation to the number of species, this food web is an extremely distinct outlier in the decreasing hyperbolic curve of $C$ versus $S$ (Fig. 5). Demonstrated here and elsewhere (Warren 1989, Cohen et al. 1990, Winemiller 1990, Hall \& Raffaelli 1991, Martinez 1991, Polis 1991, Schoenly et al. 1991, Havens 1992, Goldwasser \& Roughgarden 1993, Closs \& Lake 1994, Reagan et al. 1996, Martinez et al. 1999), most food webs that have $>40$ species have a connectance of approximately $10 \%$. Similarly, if one cal-

1982, Garrison \& Link 2000, Overholtz et al. 2000, Link \& Garrison 2002). The percentage of omnivorous species in this study is certainly larger than many other food web studies, but is also not greater than more recent and extensive food webs (Fig. 4). An interesting question arises from these observations: are organisms in marine systems more generalist and omnivorous than freshwater or terrestrial organisms, especially since systems with more specialists generally have lower connectivities (Goldwasser \& Roughgarden 1993, Polis \& Strong 1996, Reagan et al. 1996, McCann et al. 1998, Closs et al. 1999)? Or are these observations a result of the high sampling intensity and long duration of this and more recent studies?

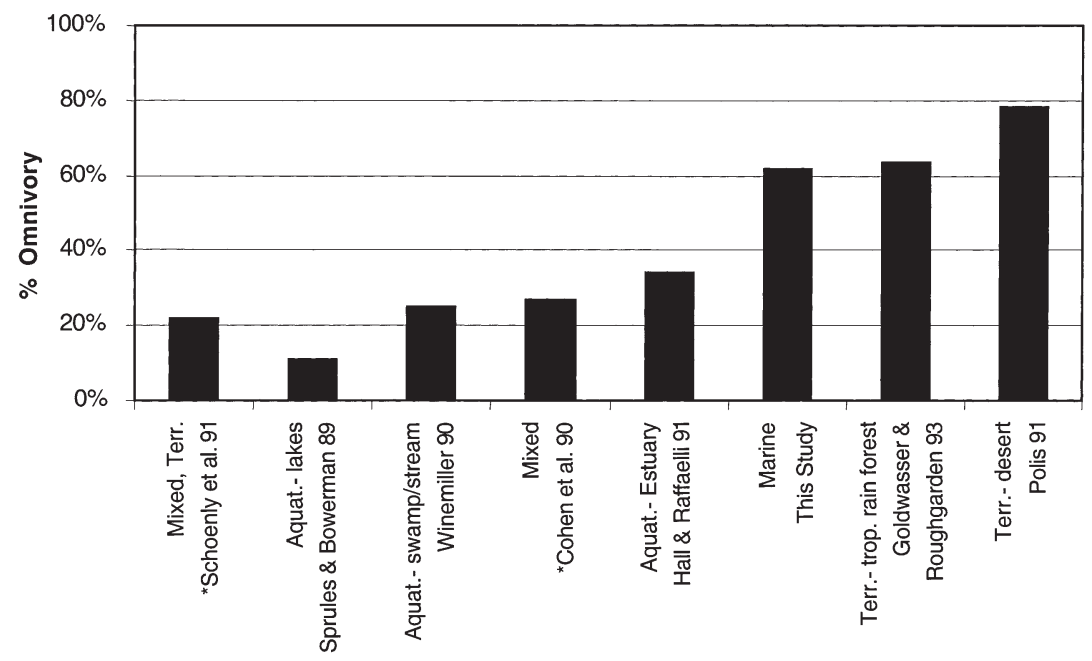

Fig. 4. Percent of omnivorous species from various food webs culates directed connectance (Martinez 1991, 1992), the value for this food web is more similar to those with 10 to 30 species $\left(C_{\text {dir }} 20\right.$ to 40$)$ than those with a similar number of species $\left(C_{\mathrm{dir}} 2\right.$ to 10$)$. I recognize the contentious nature of this relationship and that I was inclusive in my assessment of interactions (disregarding interaction strength when ascertaining linkages, some trophic aggregation, including humans, etc.). Regardless of the exact relationship, the scale of these data, both temporally and spatially, is longer and larger than most food web analyses, and precludes these observations from being mere artifact. Given that only a few marine food webs have been formally analyzed with this protocol (and those that have are generally coastal, enclosed or embayed), the openness of marine ecosystems, and the orders of magnitude in size across the ontogeny of these organisms, the unique relationship between the number of species and connectivity of this food web is in stark contrast to observations from other food webs. These data do not fully cover the entire size range and trophic levels across the life history of these organisms, and it is feasible that including egg, larval, and juvenile interactions would increase the connectivity even more. It is likely that marine ecosystems are inherently very different from terrestrial or freshwater ecosystems for the reasons mentioned above (cf. Steele 1985), and 


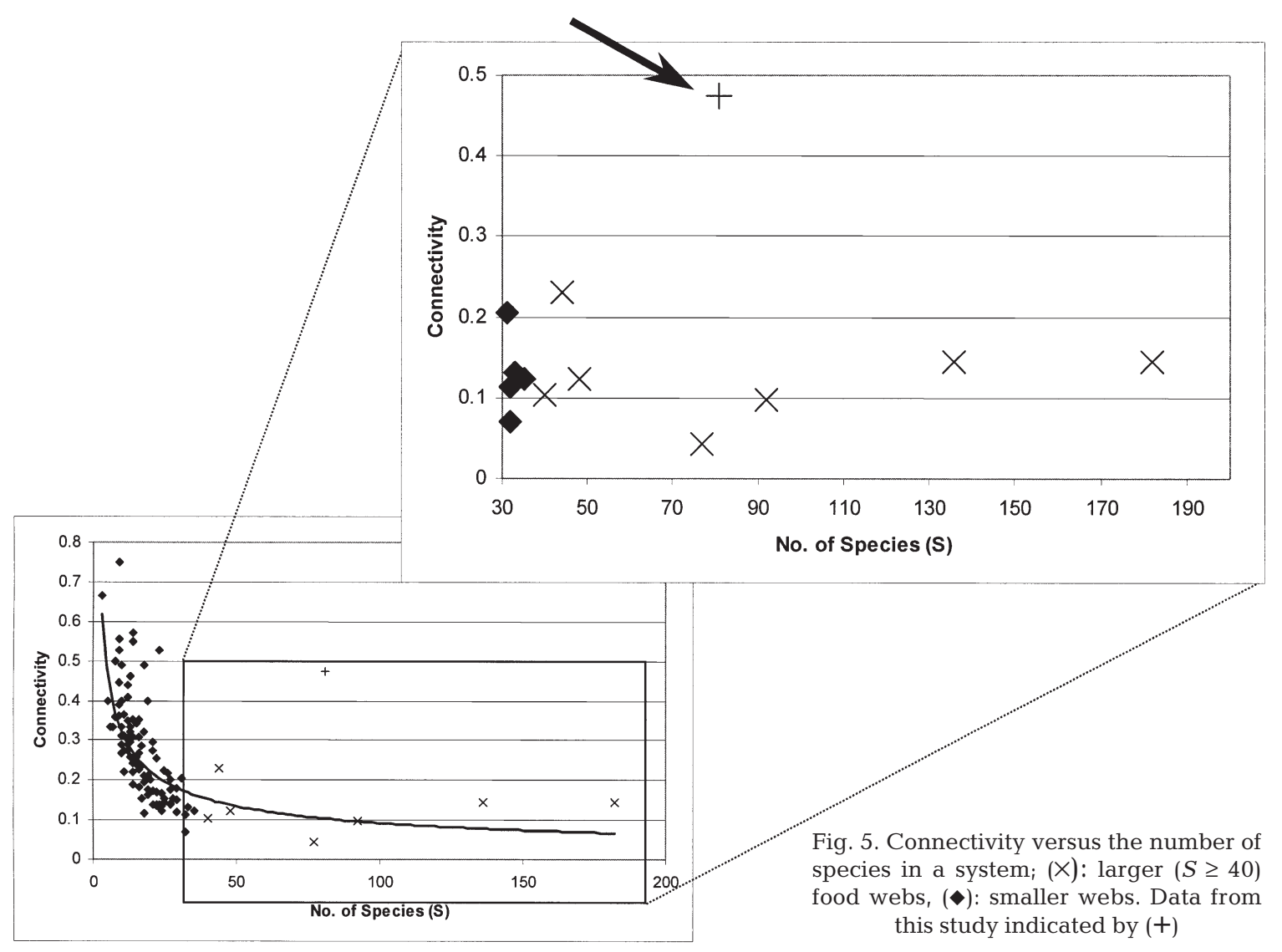

some allowance for this should be incorporated into food web theory.

Results from prior predation studies generally indicate that this web is weakly connected (Sissenwine et al. 1982, Garrison \& Link 2000, Link \& Almeida 2000). No one linkage should dominate the biomass flux in this or similar systems under stable conditions. Although there may be numerous interactions, few are of the magnitude to drive whole-system dynamics. Given the high dietary overlap and generalist feeding nature of these organisms, plus the well documented diet switching of the organisms in this system (Sissenwine et al. 1982, Garrison 2000, Garrison \& Link 2000, Overholtz et al. 2000, Link \& Garrison 2002), it appears that no one organism is highly and directly dependant on nor highly and directly impacted by populations of another species. Yet it is unclear if the loose connectivity of this system lends itself toward system stability (McCann et al. 1998, Closs et al. 1999).

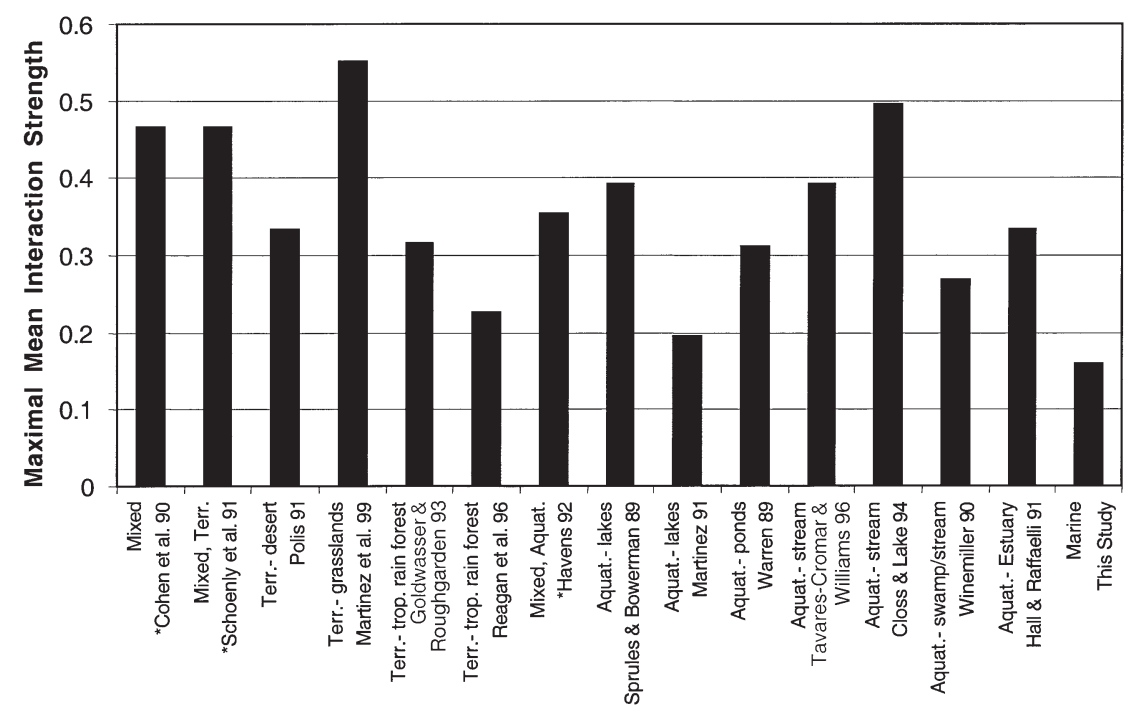

Fig. 6. Given May's (1973) mathematical constraints for Lyapunov stability, these are the maximal mean interaction strengths for various food webs 
webs, often by a factor of 2 or 3 (Fig. 6). Prior work on this food web generally suggests that species interactions occur at approximately this strength (Sissenwine et al. 1982). Yet even if this simplified calculation indicates that this system may be mathematically stable, such an inference is very likely inconclusive given that this system is precariously balanced near unstable conditions due to potential variations in interaction strength.

However, the question begs, have we already exceeded stability limits? This system has a well documented history of continued and strong perturbations, principally due to over-exploitation (Boreman et al. 1997) This history is similar to the majority of the world's marine ecosystems, highlighted by the disturbing trend of humans consuming more forage fish at lower trophic levels, lower catches per unit effort, increased endangered species listings, and over $70 \%$ of the world's fish stocks exploited at, or beyond, the maximum level that can be sustained (FAO 1997, NRC 1999). One could argue that assessing the stability of the US Northeast Shelf ecosystem or similar marine food webs is a moot point given the ongoing harvesting pressure they have experienced over the past several decades. If we assume that this system exhibits at least Lyapunov stability, then 2 points stand out. One is that with the high degree of interactions in this web, the resilience is going to be very high. That is, to return to a historical equilibrium will take a long time, presuming that it: (1) existed; (2) resembled a state where cod, haddock, and other gadoids were predominant in the demersal fish community; and( 3) we can manipulate it to do so. Second, it is likely that this system may be perturbed beyond its historical equilibrium and shifted to a new stable state.

How the populations in this and similar food webs will fluctuate from one Lyapunov equilibrium to another remains a major, if not the key management challenge for global marine resource managers. Given the complexity of marine food webs, the high degree of omnivory, and the generalist nature of most fish, it is unclear if predicting tradeoffs in biomass allocation among species in marine ecosystems is feasible. I recognize that combining the topological food web approach presented here with weighted interaction webs, network approaches, and similar energy flow analyses (e.g. Raffaelli \& Hall 1996, Ulanowicz 1996) should not only better address the connectivitystability issue, but also provide another set of tools to evaluate the allocation of biomass among marine species, particularly those of commercial importance. Finally, it is clear that the emergent properties of this marine food web are very different than their terrestrial and freshwater counterparts. In general, marine food webs are probably very distinct from their terres- trial or freshwater counterparts, implying that food web theory needs to be modified to accommodate observations from marine ecosystems.

Acknowledgements. I thank all members of the Food Web Dynamics Program of the NEFSC, past and present, for their dedicated effort at collecting, auditing, and maintaining this food habits database of unprecedented scale and scope. I thank N. Martinez, G. Sprules, B. Patten, W. Gabriel, L. Garrison, M. Fogarty, D. Dow, S. Whipple, M. Sissenwine, R. Ulanowicz and other reviewers for constructive comments on earlier versions of this manuscript. This work was supported by NOAA, NMFS, NEFSC and NOAA's Coastal Ocean Program, Georges Bank Study.

\section{LITERATURE CITED}

Arreguin-Sanchez F, Seijo JC, Valero-Pacheco E (1993) An application of ECOPATH II to the north central shelf ecosystem of Yucatan, Mexico. In: Christensen V, Pauly D (eds) Trophic models of aquatic ecosystems. ICLARM Conf Proc 26, p 269-278

Baird D, Ulanowicz RE (1989) The seasonal dynamics of the Chesapeake Bay ecosystem. Ecol Monogr 59:329-364

Boreman J, Nakashima BS, Wilson JA, Kendall RL (1997) Northwest Atlantic groundfish: perspectives on a fishery collapse. American Fisheries Society, Bethesda, MD

Briand F, Cohen JE (1987) Environmental correlates of food chain length. Science 238:956-960

Christensen V, Pauly D (1993) Flow characteristics of aquatic ecosystems. In: Christensen V, Pauly D (eds) Trophic models of aquatic ecosystems. ICLARM Conf Proc 26, p 338-352

Closs GP, Lake PS (1994) Spatial and temporal variation in the structure of an intermittant-stream food-web. Ecol Monogr 64:1-21

Closs GP, Watterson GA, Donnelly PJ (1993) Constant predatorprey ratios: an arithmetic artifact? Ecology 74:238-243

Closs GP, Balcombe SR, Shirley MJ (1999) Generalist predators, interaction strength and food-web stability. Adv Ecol Res 28:93-126

Cohen JE (1989) Ecologist co-operative web bank. Version 1.0. Machine-readable data base of food webs. Rockefeller University, New York

Cohen JE, Newman CM (1988) Dynamic basis of food web organization. Ecology 69:1655-1664

Cohen JE, Briand F, Newman CM (1990) Community food webs: data and theory. Springer-Verlag, New York

Cohen JE, Bearer RA, Cousins SH, De Angelis DL and 19 others (1993) Improving food webs. Ecology 74:252-258

Crowder LB, Reagan DP, Freckman DW (1996) Food web dynamics and applied problems. In: Polis GA, Winemiller KO (eds) Food webs: integration of patterns and dynamics. Chapman and Hall, New York, p 327-336

DeAngelis DL (1992) Dynamics of nutrient cycling and food webs. Chapman and Hall, London

de Ruiter CP, Neutal A, Moore JC (1995) Energetics, patterns of interaction strengths, and stability in real ecosystems. Science 269:1257-1260

FAO (Food and Agriculture Organisation) (1997) The state of world fisheries and aquaculture 1996. FAO, Rome

Garrison LP (2000) Spatial and dietary overlap in the Georges Bank groundfish community. Can J Fish Aquat Sci 57: 1679-1691 
Garrison LP, Link JS (2000) Dietary guild structure in the fish community of the United States northeast continental shelf ecosystem. Mar Ecol Prog Ser 202:231-240

Goldwasser L, Roughgarden J (1993) Construction of a large Caribbean food web. Ecology 74:1216-1233

Goldwasser L, Roughgarden J (1997) Sampling effects and the estimation of food-web properties. Ecology 78:41-54

Gomes MDC (1993) Predictions under uncertainty: Fish assemblages and food webs on the Grand Banks of Newfoundland. Social and Economic Studies No. 51, Institute of Social and Economic Research (ISER), Memorial University of Newfoundland, St. John's

Hall SJ, Raffaelli DG (1991) Food-web patterns: lessons from a species-rich web. J Anim Ecol 60:823-842

Hall SJ, Raffaelli DG (1993) Food webs: theory and reality. Adv Ecol Res 24:187-236

Havens K (1992) Scale and structure in natural food webs. Science 257:1107-1109

Haydon D (1994) Pivotal assumptions determining the relationship between stability and complexity: an analytical synthesis of the stability-complexity debate. Am Nat 144: $14-29$

Link J, Almeida F (2000) An overview and history of the food web dynamics program of the Northeast Fisheries Science Center, Woods Hole. NOAA Tech Memo NMFS-NE-159

Link JS, Garrison LP (2002) Changes in piscivory associated with fishing induced changes to the finfish community on Georges Bank. Fish Res 55:71-86

Martinez ND (1991) Artifacts or attributes? Effects of resolution on the Little Rock Lake food web. Ecol Monogr 61: 367-392

Martinez ND (1992) Constant connectance in community food webs. Am Nat 139:1208-1281

Martinez ND (1993) Effects of resolution of food web structure. Oikos 60:403-412.

Martinez ND, Hawkins BA, Dawah HA, Feifarek BP (1999) Effects of sampling effort on characterization of food-web structure. Ecology 80:1044-1055

May RM (1973) Stability and complexity in model ecosystems. Princeton Univ Press, Princeton

McCann K, Hastings A, Huxel GR (1998) Weak trophic interactions and the balance of nature. Nature 395:794-798

Mendoza JJ (1993) A preliminary biomass budget for the northeastern Venezuela shelf. In: Christensen V, Pauly D (eds) Trophic models of aquatic ecosystems. ICLARM Conf Proc 26, p 285-297

Menge BA, Sutherland JP (1976) Species diversity gradients: synthesis of the roles of predation, competition, and temporal heterogeneity. Am Nat 110:351-369

Monaco ME, Ulanowicz RE (1997) Comparative ecosystem structure of three US Mid-Atlantic estuaries. Mar Ecol Prog Ser 161:239-254

NRC (National Research Council) (1999) Sustaining marine fisheries. National Academy Press, Washington

Overholtz WJ, Link JS, Suslowicz LE (2000) The impact and implications of fish predation on pelagic fish and squid on the eastern USA shelf. ICES J Mar Sci 57:1147-1159

Paine RT (1966) Food web complexity and species diversity. Am Nat 100:65-75

Pimm SL (1982) Food webs. Chapman and Hall, London

Pimm SL (1984) The complexity and stability of ecosystems.

Editorial responsibility: Kenneth Sherman (Contributing Editor), Narragansett, Rhode Island, USA
Nature 307:321-326

Pimm SL, Lawton JH (1978) On feeding on more than one trophic level. Nature 275:542-544

Pimm SL, Lawton JH, Cohen JE (1991) Food web patterns and their consequences. Nature 350:669-674

Polis GA (1991) Complex trophic interactions in deserts: An empirical critique of food web theory. Am Nat 138: 123-155

Polis GA, Strong DR (1996) Food web complexity and community dynamics. Am Nat 147:813-846

Polis GA, Myers CA, Holt RD (1989) The ecology and evolution of intraguild predation: Potential competitors that eat each other. Annu Rev Ecol Syst 20:297-330

Raffaelli D (2000) Trends in research on shallow water food webs. J Exp Mar Biol Ecol 250:223-232

Raffaelli DG, Hall SJ (1996) Assessing the relative importance of trophic links in food webs. In: Polis GA, Winemiller KO (eds) Food webs: integration of patterns and dynamics. Chapman and Hall, New York, p 185-191

Reagan DP, Camilo GR, Waide RB (1996) The community food web: major properties and patterns of organization. In: Reagan DP, Waide RB (eds) The food web of a tropical rain forest. Univ of Chicago Press, Chicago, p 461-510

Schoener TW (1989) Food webs from the small to the large. Ecology 70:1559-1589

Schoenly K, Beaver RA, Heumier TA (1991) On the trophic relations of insects: a food web approach. Am Nat 137: $597-638$

Sherman K, Grosslein M, Mountain D, Busch D, O'Reilly J, Theroux R (1996) The Northeast Shelf ecosystem: an initial perspective. In: Sherman K, Jaworski NA, Smayda TJ (eds) The Northeast Shelf ecosystem: assessment, sustainability, and management. Blackwell Scientific Publications, Oxford, p 103-126

Sissenwine MP, Brown BE, Palmer JE, Essig RJ, Smith W (1982) Empirical examination of population interactions for the fishery resources off the northeastern USA. Can Spec Publ Fish Aquat Sci 59:82-94

Solow A, Beet A (1998) On lumping species in food webs. Ecology 79:2013-2018

Sprules WG, Bowerman JE (1988) Omnivory and food chain length in zooplankton food webs. Ecology 69:418-426

Steele JH (1985) A comparison of terrestrial and marine ecological systems. Nature 313:355-358

Tavares-Cromar AF, Williams DD (1996) The importance of temporal resolution in food web analysis: Evidence from a detritus based stream. Ecol Monogr 66:91-113

Ulanowicz RE (1996) Trophic flow networks as indicators of ecosystem stress. In: Polis GA, Winemiller KO (eds) Food webs: integration of patterns and dynamics. Chapman and Hall, New York, p 358-368

Warren PH (1989) Spatial and temporal variation in the structure of a freshwater food web. Oikos 55:299-311

Warren PH (1994) Making connections in food webs. Trends Ecol Evol 9:136-141

Winemiller KO (1990) Spatial and temporal variation in tropical fish trophic networks. Ecol Monogr 60:27-55

Winemille KO, Polis GA (1996) Food webs: what can they tell us about the world? In: Polis GA, Winemiller KO (eds) Food webs: integration of patterns and dynamics. Chapman and Hall, New York, p 1-22

Submitted: May 21, 2001; Accepted: August 30, 2001

Proofs received from author(s): March 8, 2002 